\title{
Microbiology gaining ground after lean years
}

Jonathan Knight, New Orleans

Of the thousands of microbes known to science, $99 \%$ have yet to be cultured in a dish. But unless they can be grown in the laboratory, there is little hope that their physiology or behaviour will ever be well understood.

Solving this culture problem was just one of the challenges outlined to microbiologists who attended a special, 24 May symposium on the future of their discipline at the annual meeting of the American Society for Microbiology in New Orleans.

With the rise of molecular biology over the past half-century - and that of biotechnology in its wake - researchers who study the life cycles and habitats of microbes have acquired something of a stuffy image. As research funding shifted to the fashionable areas of molecular and cell biology, microbiology faculty positions were lost, and in some cases whole departments were closed.

But now, the symposium was told, microbiology is regaining some of its lustre. Part of the revival is due to growing public concern about emerging diseases and biological weapons. Another contributing factor is the speed with which researchers are sequencing the full genomes of various microbes.

Almost 200 bacteria and fungi have been completely sequenced to date. This makes microbes particularly useful for answering big-picture questions about biodiversity and evolution, says Moselio Schaechter, a mushroom biologist and visiting scholar at the University of California, San Diego. "We are entering a golden age of microbiology," enthuses Schaechter, who moderated a meeting in Charleston, South Carolina, last September to identify growth areas in the field.

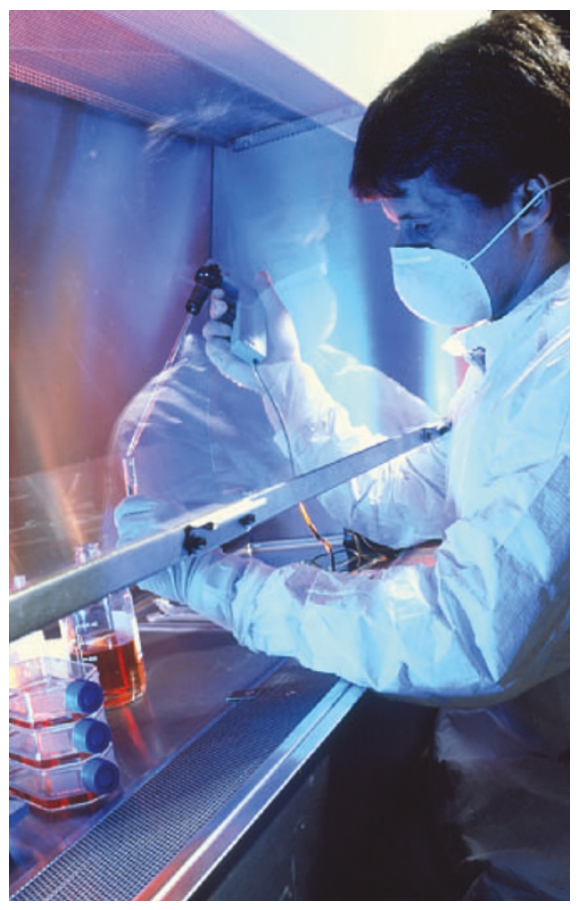

Popular culture: the study of bacteria and viruses is experiencing a resurgence.

These sequences offer new opportunities for microbiologists. They could aid the study of gene sharing, an important factor in evolution: bacteria are the most promiscuous gene exchangers known - up to $60 \%$ of the genes in the gut bacterium Escherichia coli can be different in different strains. No one yet knows how, or why, this is so.

Rapid sequencing enables entire communities of microbes to be identified from a single sample of water, as shown in projects such as the study of acidic run-off from mines run by the Joint Genome Institute in Walnut Creek, California. The approach ensures that all microbial species in a sample can be found, not just those that grow readily in culture.

"This will be a key part of how we look at complex populations in the future," predicts Stanley Malloy, director of the Center for Applied and Experimental Genomics at San Diego State University and president-elect of the microbiology society. By monitoring genomes of entire populations, microbiologists hope to answer perplexing questions, such as why bacterium-infecting viruses that live in the ocean carry genetic instructions for synthesizing cholera toxin. "Why are they there?" asks Malloy. "Nobody knows."

One sure sign that times are changing is that microbiologists are finding jobs in university departments outside biology, says Roberto Kolter, who studies sheets of bacteria, known as biofilms, at Harvard Medical School in Boston. Earth sciences departments hire them to study the microbial processes that shape rock, and astronomy departments want help from experts on microbes living in extreme environments to investigate the possibility of life on other planets.

Harvard, which lacks a microbiology department, established a Microbial Sciences Initiative earlier this year that will create faculty positions for microbiologists elsewhere in the university. Although their primary labs will still be distributed around campus, the faculty members will meet regularly and share some laboratory space.

Regardless of the form microbiology takes, participants at the meeting expect that it will make a big contribution to our understanding of life on Earth. "Microbes rule this world," Schaechter says.

\section{Japan announces follow-up to human genome project}

\section{David Cyranoski, Tokyo}

Japan is launching the Genome Network, a five-year, ¥15-billion (US\$130-million) initiative that will attempt to build on the human genome project and systematically study the function of all human genes.

The initiative will collate experimental data on all 30,000 human genes, says Yoshihide Hayashizaki, a researcher at the Genomic Sciences Center (GSC) in Yokohama and member of the project's steering committee. The GSC will play a central role, but Japan's science ministry will divide the work among researchers across the country. Organizers plan to start recruiting teams next week.

Details of the initiative remain to be decided. Like the US Encyclopedia of DNA
Elements (ENCODE) project, it aims at a systematic, comprehensive analysis of the human genome. Japan's project will focus on how the information in the genome is expressed, says Yoshiyuki Sakaki, who is head of the GSC and also on the steering committee. It will look at the interaction between genes and the proteins known as transcription factors that initiate expression of them, he explains.

The project hopes to assemble a library of complementary DNA corresponding to every human gene. The collections of cDNA held by Hayashizaki's centre and by Sumio Sugano of University of Tokyo's Institute of Medical Science are already among the largest in the world, notes Sakaki. "We need to take advantage of this," he says.
Takehiko Sasazuki, head of research at the International Medical Center of Japan in Tokyo and chairman of the steering committee, says the scale of the project will help ensure its success. "By putting together all these data, we will be able to find unexpected phenomena."

Sakaki and others say that the initiative will begin at a national level but may collaborate with projects in other countries later. "First we have to run our own system and then we can figure out how to cooperate," says Sakaki. "We need a year."

He adds that details of the project will be agreed at a final steering committee meeting on 31 May, and that work will begin in September, with funding already assured from the science ministry. 